\title{
INVESTIGATIONS OF GROUND-WATER RESOURCES OF THE LOWER COLORADO RIVER
}

By G. E. Hendrickson, Project Geologist

In order to determine the overall ground-water potential of the area, we need to know the geologic environment and the water-bearing and storage characteristics of all aquifers and associated earth materials. But this is only part of the picture. We must know also how water moves through these materials and how the ground water relates to surface water.

To define the geologic environment, we are making a reconnaissance study of the surface and subsurface geology of the entire area. Preliminary maps of the surface deposits of the flood plain of the Lower Colorado River and of the Imperial Valley have been prepared.

We are collecting logs of existing wells from all possible sources. Where time and available manpower permit, we are collecting formation samples and preparing logs of the materials penetrated by private wells being drilled in strategic locations. To supplement this information, we are having several test wells drilled with project funds. The locations and depths of these test wells are determined by an analysis of existing geologic and hydrologic information. In addition to the deep test wells obtained under contract, we are also obtaining shallow test wells by means of a power auger.

The subsurface information obtained from all sources is being analyzed, and geologic sections, fence diagrams, and isopachous and structural maps are being prepared to illustrate, in as great detail as possible, the subsurface character of the earth materials. Together with the surface maps, they show the geologic environment that affects the water resources of the area.

The fence diagram prepared by Harshbarger and Lance (1956) shows a "coarse gravel aquifer" at about sea level elevation in the Yuma area. Although the "coarse gravel aquifer" is shown as a continuous and rather uniform unit, Harshbarger warned that alluvial deposits such as this normally vary considerably from place to place. The maps and diagrams now being prepared include informa tion from a number of wells and test holes which have been drilled since the 1956 report was prepared. They show the predicted variability of the aquifer.

The ground-water geologist or hydrogeologist looks at earth materials both as reservoirs and as conduits of ground water. While mapping the surface formations, he is also evaluating their water-bearing and 
storage characteristics. The geologist observing a well-drilling operation does not simply describe the physical appearance of the well cuttings; he also notes the apparent permeability and storage capacity of the material penetrated. He records the depth at which water is found in the well and the static level of water found at different depths. He takes samples of the water from all important aquifers and measures the specific conductance of the water in order to determine changes in the amount of dissolved solids of the water.

Another source of information is the well inventory. We are visiting representative wells in all parts of the project area and recording information on depths of wells, materials encountered, quantity and quality of water yielded by the wells, and static level of the water in wells. The well inventory is essentially completed in the Yuma area. Inventory of wells in the Palo Verde and Imperial Valley areas is about half completed. In the remainder of the project area, only a brief reconnaissance inventory has been made.

Pumping tests of one or more wells in an aquifer yield useful information on the availability of water from the aquifer. We have made brief pumping tests on the city wells at Indio, in Coachella Valley, and have assisted in tests on the Bureau of Reclamation drainage wells in the South Gila Valley. Other tests are planned on existing wells near Needles, Parker, and Blythe, and in the Yuma area. Pumping tests will also be made on most of the test wells being drilled by the Survey. From these tests we hope to obtain at least approximate values of transmissibility and useful information on the storage characteristics of the aquifers.

Water-table maps show the general direction of ground-water movement. If the geologic setting and the permeabilities of the aquifers are known, the water table map can be used to compute the quantity of ground-water moving through any cross-section of an aquifer.

To obtain the information needed to prepare water-table maps, we have established a network of observation wells. Most of these are measured weekly or monthly; a few are equipped with continuous recording gages. The records obtained from these wells have been supplemented by single measurements of the water levels in wells inventoried and by the extensive records obtained from the Bureau of Reclamation and the several irrigation districts.

We have prepared a water-table map from the sources described above, which is still preliminary and subject to revision. Not all the assumptions inherent in any water table map are valid in this one. For example, it is assumed that water levels in wells used as controls were measured 
at about the same time, or that there was relatively little change in water levels between the different measurements. Water levels used in this map are chiefly those obtained during the winter 1960-61, but some are earlier or later measurements. Another assumption, that all wells tap the same aquifer, may not be valid in places. As additional data becomes available, the map will be modified and refined.

Water-table maps show only the horizontal component of ground-water motion. The vertical component can be determined by constructing a cluster or battery of observation wells which tap the aquifer or aquifers at several depths. Such well clusters have been constructed in the Yuma area and Imperial Valley; more will be installed in othe $r$ areas where vertical gradients in aquifers are significant.

When we have obtained the needed information on the geologic environment and water-bearing character and storage characteristics of the earth materials and the movement of water through these materials, we should be able to evaluate the overall ground-water potential of the Lower Colorado River area. We should be able to determine how much water can be obtained from storage in each basin and how much will be intercepted from surface streams under various conditions of development. We should be able to predict and evaluate drainage problems resulting from application of irrigation water to the land and indicate the effectiveness of remedial measures. We should, in fact, have the knowledge necessary to cope with all ground-water problems present or future - in the study area.

Unfortunately, we can never hope to obtain all the information needed to provide precise quantitative answers to all ground-water questions. For economic and practical reasons our data can never be complete enough. Our description of the geologic environment and of the transmissibility of aquifers must of necessity be generalized. Because of these necessary generalizations, quantitative answers to ground-water problems may be subject to appreciable error, and some of the conclusions reached must be considered tentative.

Nevertheless, our studies will make possible a useful evaluation of the ground-water potential of the Lower Colorado River area. This evaluation will be subject to error, but we should be able to determine the probable margin of error in all components of the evaluation. Our conclusions should be of substantial value in planning the utilization of all water resources of the area.

\section{References Cited.}

Harshbarger, J.W. and J.F. Lance, 1956, Rock units in the Yuma area, in Brown, R. H., Harshbarger, J.W., and Thomas, H. E., Analysis of basic data concerning ground water in the Yuma area, Arizona: U. S. Geological Survey open file report, 1956, p. 13-26. 


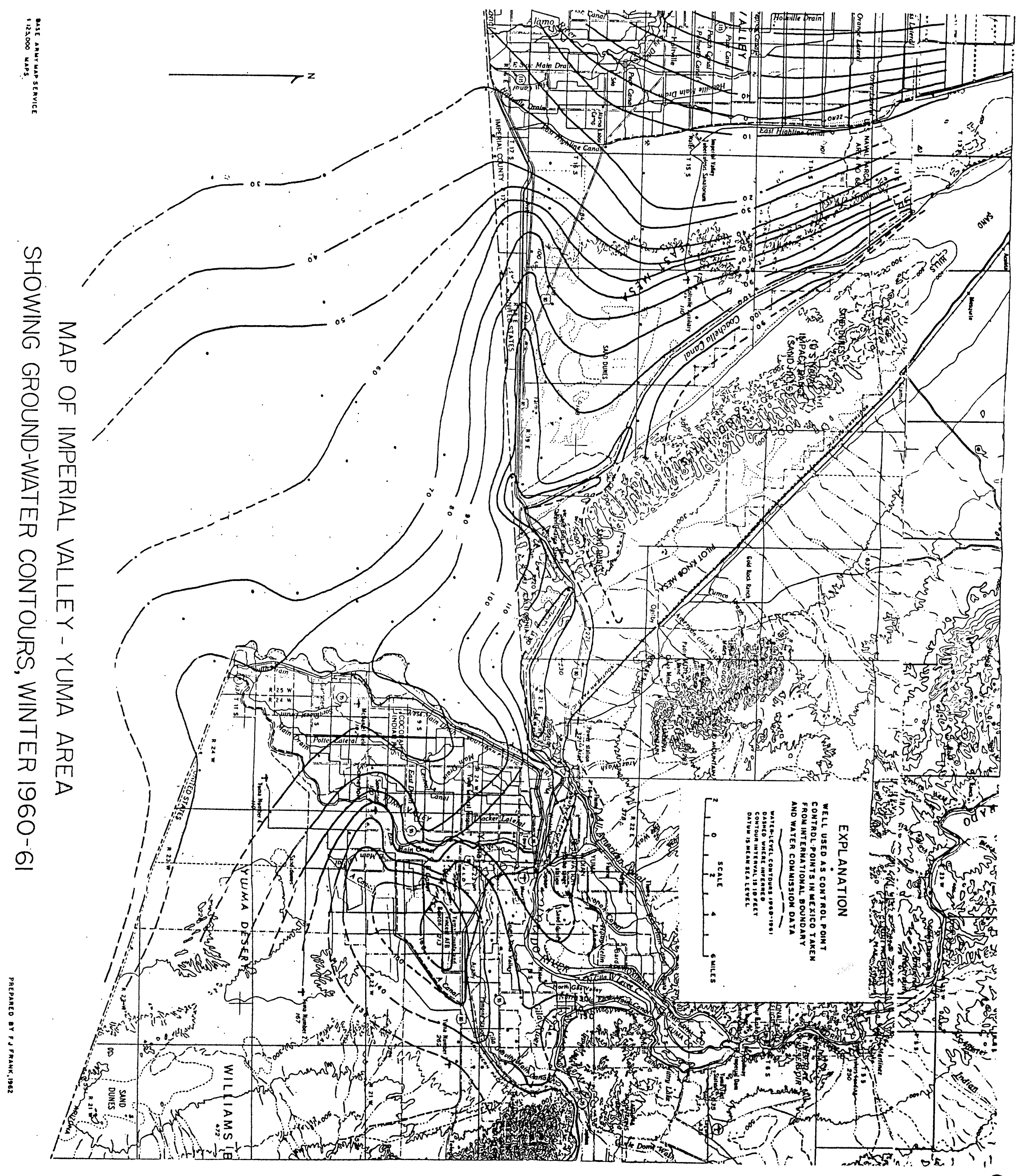




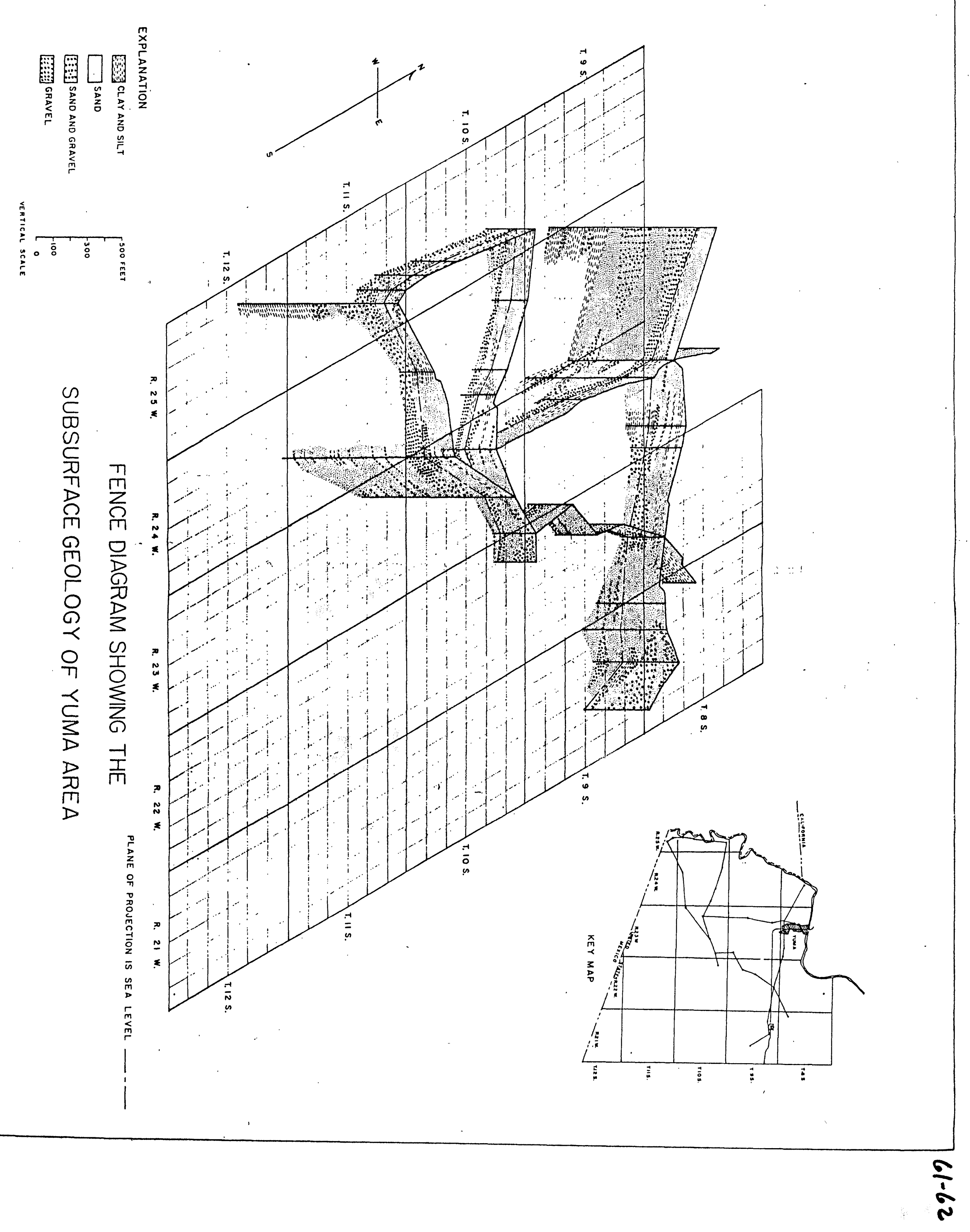

